\title{
Urokinase-type plasminogen activator in carcinomatous pleural fluid
}

\author{
H. Ishikawa*+, H. Satoh+, S. Hasegawa+, T. Yazawa**, T. Naito*+, \\ Y.T. Yamashita + , M. Ohtsuka+, T. Ogata**, H. Kamma**
}

Urokinase-type plasminogen activator in carcinomatous pleural fluid. $H$. Ishikawa, $H$. Satoh, S. Hasegawa, T. Yazawa, T. Naito, Y.T. Yamashita, M. Ohtsuka, T. Ogata, H. Kamma. @ERS Journals Ltd 1997.

ABSTRACT: Urokinase-type plasminogen activator (u-PA) is known to be secreted by malignant cells during proliferation and migration, and is associated with tumour cell invasion and metastasis. This study was undertaken to evaluate whether u-PA is significantly increased in carcinomatous pleural fluids compared to those due to other aetiologies, and to identify the cells in the pleural space that are involved in its accumulation.

Using an enzyme-linked immunosorbent assay, we quantified u-PA in the pleural fluid specimens of $\mathbf{4 0}$ patients with carcinomatous pleuritis, 18 with tuberculosis, 18 with parapneumonic pleuritis and 11 with congestive heart failure (CHF).

The level of u-PA was elevated in carcinomatous pleural fluid compared with the level in transudative pleural fluid from patients with $\mathrm{CHF}(\mathrm{p}<0.0001)$. The levels of u-PA were not statistically different between patients with cancer and tuberculosis, or between patients with cancer and pneumonia. The levels of u-PA in patients who did not respond to chemical pleurodesis were significantly higher than those who had complete response $(p=0.0001)$. In immunocytochemical and immunoblotting studies, cancer cells in pleural fluids as well as mesothelial cells contained u-PA. u-PA was detected in the culture supernatants of viable pleural cells in the majority of patients with carcinomatous pleuritis.

Our results suggest that local release of urokinase-type plasminogen activator by viable cells, including cancer cells and mesothelial cells, may affect the levels of urokinase-type plasminogen activator in pleural fluids. Eur Respir J 1997; 10: 1566-1571.
*Dept of Internal Medicine, Tsukuba Medical Center Hospital, Ibaraki, Japan. +Dept of Respiratory Medicine, Institute of Clinical Medicine, University of Tsukuba, Ibaraki, Japan. **Dept of Pathology, Institute of Basic Medical Sciences, University of Tsukuba, Ibaraki, Japan.

\section{Correspondence: H. Satoh}

Dept of Respiratory Medicine Institute of Clinical Medicine University of Tsukuba

Tsukuba 305

Ibaraki

Japan

Keywords: Carcinomatous pleuritis parapneumonic pleuritis tuberculous pleuritis urokinase-type plasminogen activator

Received: January 161996

Accepted after revision January 151997

This work was supported, in part, by Grants from Ibaraki Prefecture and from University of Tsukuba.
The plasminogen activator (PA)-plasminogen activator inhibitor (PAI) system plays an important role in many physiological and pathological processes, including tumour cell invasion and metastasis $[1,2]$. It has been demonstrated that tumour tissues have a higher content of extractable urokinase-type plasminogen activator (u-PA) compared to normal tissues [3, 4]. Furthermore, it has been shown that u-PA is secreted by several kinds of malignant cell during proliferation and migration [5-8].

In carcinomatous pleuritis, it is currently thought that abnormalities of coagulation and fibrinolysis in the pleural space might be associated with the formation of profuse pleural fluids. It has not been fully determined which cells regulate fibrinolytic activity. Although PAI1 is abundant in inflamed and carcinomatous pleural fluid $[9,10]$, comparatively little is known about the presence of and the role played by u-PA in both types of pleuritis $[10,11]$. In the present study, we assessed the involvement of u-PA, one of the most crucial factors in the fibrinolytic system, in carcinomatous and inflamed pleuritis. We investigated which cells in the pleural space contained u-PA. The clinical significance of u-PA levels in carcinomatous pleuritis as a predictive tool in chemical pleurodesis is also discussed.

\section{Materials and methods}

\section{Patient groups and collection of pleural fluid}

Using a standard thoracocentesis technique, pleural fluids were obtained from 87 hospitalized patients. All 40 patients with carcinomatous pleural fluid had pulmonary adenocarcinoma which is the leading cause of malignant pleural fluids at our hospital. Bronchoscopic tumour biopsy was performed in all patients. The diagnosis of adenocarcinoma was made on the basis of histological specimen. The patients were enrolled only when they were proven to have malignant effusion, confirmed by cytology of the fluid or percutaneous pleural biopsy.

Intracavitary chemical sclerosing treatment with a streptococcal preparation, OK-432 (Chugai Pharmaceutical Co., Tokyo, Japan) [12], was performed in 27 of the 40 patients with carcinomatous pleuritis. Informed consent was obtained before the procedure was undertaken. The remaining 13 patients did not undergo pleurodesis because of their poor performance status, their refusal to undergo the treatment, or the presence of loculated fluid. Before the pleurodesis was initiated, the pleural fluid was maximally drained by a chest tube. The criteria 
adopted by PALADINE et al. [13] were used to assess the response to the sclerosing agent. The term "responder" defined those patients who had complete response, with no further accumulation of fluid for more than 30 days. The term "nonresponder" defined those patients who had partial response, with recurrence of effusion less than $50 \%$ of the original volume within 30 days after treatment, and patients who showed reaccumulation of effusion more than $50 \%$ of the original volume within 30 days of treatment.

Benign pleural fluid was taken from 18 patients with tuberculosis, 18 with parapneumonic pleuritis, and 11 with congestive heart failure (CHF). Pleural fluid was defined as tuberculous by showing the growth of $\mathrm{Myco-}$ bacterium tuberculosis on culture of pleural fluid and/or sputa, or granulomas in the biopsied specimen of pleura, and with a favourable response to antituberculosis therapy [14]. Parapneumonic fluid was defined as that with a glucose concentration greater than $40 \mathrm{mg} \cdot \mathrm{dL}^{-1}$ and with no organisms seen on Gram staining or found on culture of pleural fluid in patients with bacterial pneumonia [14]. All pleural fluids from patients with CHF were transudates and fluids from other diseases were exudates, using criteria with serum and pleural fluid protein and lactic acid dehydrogenase (LDH) values [15].

The pleural fluids were immediately centrifuged to remove cells and debris, and were then stored at $-30^{\circ} \mathrm{C}$ for measurement of u-PA.

\section{Cancer cell line derived from pleural fluid TKB-30}

The human pulmonary adenocarcinoma cell line, TKB30, which was derived from carcinomatous pleural fluid, was established in our laboratory in 1993 [9, 16]. The cancer cells were cultured in Dulbecco's modified Eagle's medium (DMEM; Gibco, Grand Island, NY, USA) supplemented with $5 \%$ foetal bovine serum (FBS; M.A. Bioproducts, Walkersville, MD, USA) in a humidified $5 \% \mathrm{CO}_{2}$ atmosphere.

\section{Enzyme-linked immunosorbent assay (ELISA) for u-PA}

An ELISA for u-PA was performed in all pleural fluid samples, using a commercially available kit (Biopool, Umeå, Sweden). u-PA standards were used to generate an absorbance curve, from which the duplicate values for each pleural fluid sample were read and averaged. The lower limit of detection was $0.5 \mathrm{ng} \cdot \mathrm{mL}^{-1}$. Values below this level were assumed to be zero.

\section{Immunoblotting of pleural fluid}

The molecular weight (MW) of u-PA in the different groups of 32 exudative pleural fluids (16 patients with carcinoma, 8 patients with tuberculosis, 8 patients with parapneumonic pleuritis) was evaluated using the immunoblotting method, and was compared with that in the cell lysate or the culture supernatant of TKB-30 cells. The analysis was performed as described by Hollas et al. [17]. Pleural fluid was electrophoresed in a $12.5 \%$ polyacrylamide gel, and the dissolved proteins were transferred to a nitrocellulose filter. The filter was block- ed with a $3 \%$ bovine serum albumin (BSA) solution and incubated with a 1:5,000 dilution of monoclonal antibody to human u-PA (American Diagnostica, Greenwich, CT, USA). It was then washed extensively with phosphate-buffered saline (PBS) containing $0.05 \%$ Tween20 (PBS-T) and incubated with peroxidase-labelled secondary antibody. Thereafter, it was washed with PBS$\mathrm{T}$ and exposed to X-ray film after completion of the chemiluminescence reaction, using enhanced chemiluminescence (ECL) (Amersham Life Science, Buckinghamshire, UK).

\section{u-PA production by viable cells from pleural fluids}

To evaluate the capacity for $\mathrm{u}-\mathrm{PA}$ production by viable cells in pleural fluids or the TKB-30 cells, an in vitro study was undertaken. The viable cells were obtained from the pleural fluid of six patients with carcinomatous pleuritis, four patients with tuberculosis, and two patients with parapneumonic pleuritis. Cells from the pleural fluid were isolated by Ficoll-isopaque (Pharmacia Fine Chemicals, Uppsala, Sweden) density gradient centrifugation. The band of mononuclear cells at the interface of the gradient was removed, and the cells were washed twice with PBS. The $15 \times 10^{4}$ viable pleural cells or $10 \times 10^{4}$ TKB-30 cells were plated in $9 \mathrm{~cm}^{2}$ plastic culture dishes, and were cultured in DMEM supplemented with 5\% FBS. Approximately $20 \%$ of these viable cultured cells were cancer cells in carcinomatous pleural fluids. After 4 days of culture, the culture supernatants were collected, and cells and cell debris were removed by centrifugation. Less than $30 \%$ of the plated cells were alive both in malignant and nonmalignant pleural fluids. The concentration of u-PA was assayed by ELISA. u-PA was not detected in DMEM with 5\% FBS.

\section{Immunohistochemical staining for $u-P A$}

Freshly isolated pleural cells were also cultured on glass slides in plastic dishes, followed by fixation with 95\% ethanol. The fixed cells were washed with PBS and stained according to the standard immunohistochemical procedure [18], using a monoclonal antibody against human u-PA (American Diagnostica, Greenwich, CT, USA). A negative control, in which the primary antibody was omitted, showed negative staining.

\section{Statistical analysis}

Comparison between the two groups was made using the Mann-Whitney U-test and the Chi-squared test. A p-value less than 0.05 was considered significant. Values are expressed as mean \pm standard deviation (SD).

\section{Results}

\section{u-PA in pleural fluid}

The concentration of u-PA was elevated in carcinomatous pleural fluid (mean \pm SD $14.2 \pm 20.1 \mathrm{ng} \cdot \mathrm{mL}^{-1}$ ) compared with the level in transudative pleural fluid from patients 
with CHF $\left(1.9 \pm 1.4 \mathrm{ng} \cdot \mathrm{mL}^{-1}\right)$. The difference was significant $(\mathrm{p}<0.0001)$ (fig. 1). In the benign pleural fluid, there were also differences according to the underlying diseases. The levels of u-PA in tuberculous pleural fluid $\left(4.8 \pm 2.0 \mathrm{ng} \cdot \mathrm{mL}^{-1}\right)$ and in parapneumonic pleural fluid $\left(9.6 \pm 10.0 \mathrm{ng} \cdot \mathrm{mL}^{-1}\right)$ were higher than the level in the transudates ( $\mathrm{p}=0.001$ and $\mathrm{p}=0.002$, respectively). However, u-PA levels were not statistically different between patients with cancer and tuberculosis $(\mathrm{p}=0.184)$, or between patients with cancer and pneumonia $(\mathrm{p}=$ $0.512)$. The level of $\mathrm{u}-\mathrm{PA}$ in exudates $\left(1.9 \pm 1.4 \mathrm{ng} \cdot \mathrm{mL}^{-1}\right)$ was higher than that in transudates $(p=0.001)$.

In order to discriminate malignant and nonmalignant pleural fluids, we determined the cut-off levels of u-PA using the operating characteristics curve analysis [19]. It was set to $6.2 \mathrm{ng} \cdot \mathrm{mL}^{-1}$, which gave a sensitivity of $50 \%$ and specificity of $57 \%$. As shown in figure 1 , the cut-off levels of u-PA, with such a wide overlap, are not useful as a discriminatory diagnostic test.

The u-PA/total protein ratio for the pleural fluid from each disease was examined to clarify the mechanism behind the increased level of u-PA (table 1). The carcinomatous group had significantly higher $\mathrm{u}-\mathrm{PA} /$ total protein ratios than the CHF group $(\mathrm{p}=0.045)$, which suggest augmented production of u-PA in the pleural space of the patients with carcinomatous pleuritis, in contrast with the permeation of protein in CHF.

\section{$u-P A$ and response to chemical pleurodesis}

In 27 patients with carcinomatous pleuritis treated with OK-432 by the intrapleural route, 13 (48\%) showed

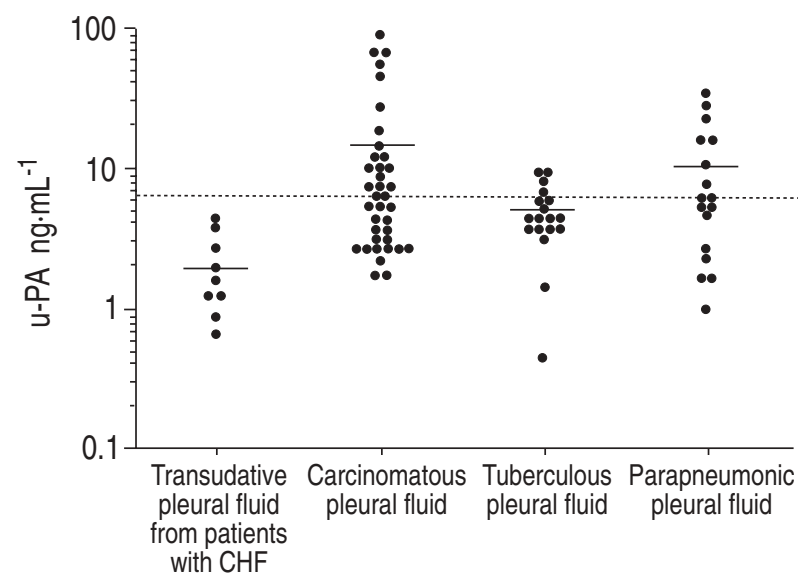

Fig. 1. - Levels of urokinase-type plasminogen activator (u-PA) in transudative pleural fluid from patients with congestive heart failure $(\mathrm{CHF})$, carcinomatous pleural fluid, tuberculous pleural fluid, and parapneumonic pleural fluid. Each point represents one pleural fluid value. The bars indicate the mean values of u-PA in pleural fluids among each groups of patients. A dotted line indicates the cut-off level.

Table 1. - u-PA/total protein ratios in pleural fluid from patients with different diseases

\begin{tabular}{lcc}
\hline Diagnosis & $\mathrm{u}-\mathrm{PA} /$ total protein & $\mathrm{p}$-value* \\
\hline CHF & $0.94 \pm 0.60$ & - \\
Cancer & $2.69 \pm 3.46$ & 0.045 \\
Parapneumonia & $2.52 \pm 2.63$ & 0.065 \\
Tuberculosis & $1.10 \pm 0.40$ & 0.398 \\
\hline
\end{tabular}

u-PA: urokinase-type plasminogen activator; CHF: congestive heart failure. $*$ : p-values are shown versus CHF.
Table 2. - Characteristics of the patients with carcinomatous pleuritis who were treated by chemical pleurodesis

\begin{tabular}{lccc}
\hline & Responder & $\begin{array}{c}\text { Non- } \\
\text { responder }\end{array}$ & p-value \\
\hline Patients n & 13 & 14 & NS \\
Age yrs & $58 \pm 15$ & $67 \pm 9$ & NS \\
Sex M/F & $6 / 7$ & $9 / 5$ & NS \\
Characteristics of fluid & & & \\
Specific gravity & $1.035 \pm 0.002$ & $1.034 \pm 0.005$ & NS \\
Total protein g.dL-1 & $4.6 \pm 0.6$ & $4.6 \pm 0.9$ & NS \\
LDH IU.L ${ }^{-1}$ & $604 \pm 281$ & $1069 \pm 1102$ & NS \\
\hline
\end{tabular}

Responder: patients who responded to chemical pleurodesis; nonresponder: those who did not respond. Criteria for the assessment of response were those adopted by PaLADINE et al. [13]. M: male; F: female; LDH: lactic acid dehydrogenase; NS: nonsignificant.

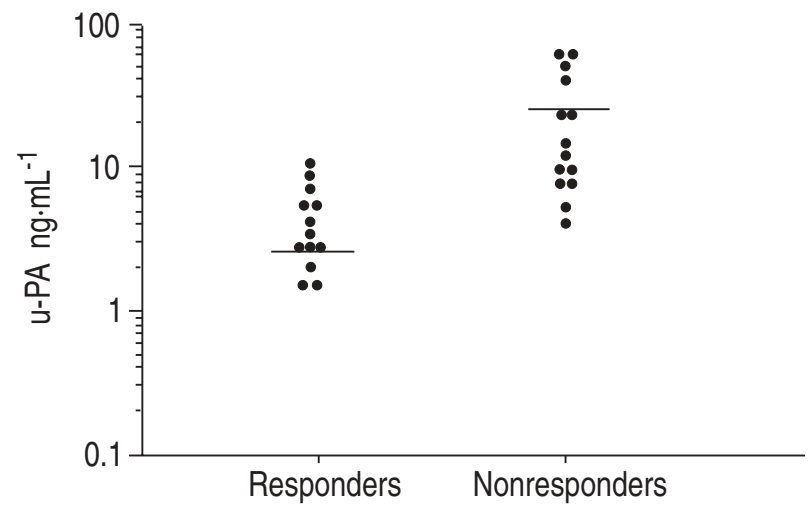

Fig. 2. - Comparison of concentration of urokinase-type plasminogen activator (u-PA) in responders and nonresponders to chemical pleurodesis. The bars indicate the mean values of u-PA in pleural fluids among each group of patients.

a complete response. There were no significant differences between the responders and the nonresponders with regard to age, gender, or characteristics of the fluid (table 2). As shown in figure 2, u-PA concentration in pleural fluid in the nonresponders $\left(26.0 \pm 20.6 \mathrm{ng} \cdot \mathrm{mL}^{-1}\right)$ was higher than that in the responders $\left(4.6 \pm 2.6 \mathrm{ng} \cdot \mathrm{mL}^{-1}\right)$ $(\mathrm{p}=0.0001)$.

\section{Immunoblotting}

Figure 3 shows Western blot analysis of pleural effusions, TKB-30 cell lysate and its supernatant. The immunoblotting was performed in 32 exudative pleural effusions. Figure 3 presents the typical pattern for adenocarcinoma ( 2 cases), tuberculosis (1 case), and pneumonia ( 1 case). The remaining 28 effusions showed the same patterns. The observed MW was $55 \mathrm{kDa}$, which was the expected size of u-PA. In this experiment, we also observed weak and broad bands ranging 80-90 $\mathrm{kDa}$. In the cell lysate and the culture supernatants of TKB-30 cells, the observed MW of u-PA was $55 \mathrm{kDa}$ (fig. 3).

\section{$u-P A$ release by viable cells from pleural fluids}

u-PA was detected in the culture supernatants of viable pleural cells from 5 of the 6 patients with carcinomatous pleuritis $\left(6.1 \pm 10.7 \mathrm{ng} \cdot \mathrm{mL}^{-1}\right)$. In one of four patients 


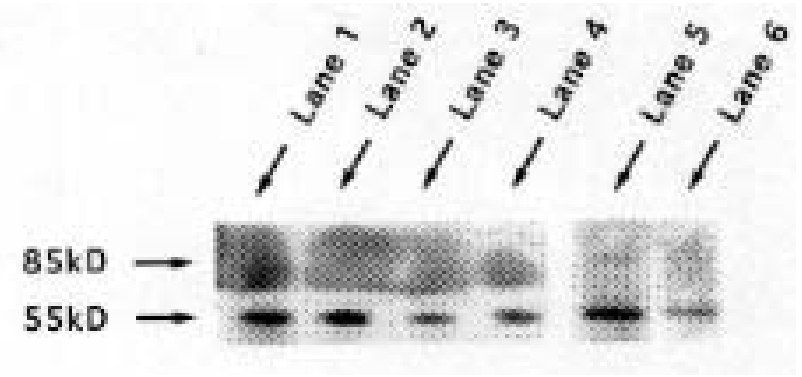

Fig. 3. - Western blot analysis of pleural fluid from patients with carcinomatous pleuritis (lanes 1 and 2), patient with tuberculous pleuritis (lane 3), and patient with parapneumonic pleuritis (lane 4). Lanes 5 and 6 were cell lysate and culture supernatant of TKB-30 cell, respectively. In every lane, the observed molecular weight was 55 $\mathrm{kDa}$, which was the expected value of urokinase-type plasminogen activator (u-PA).
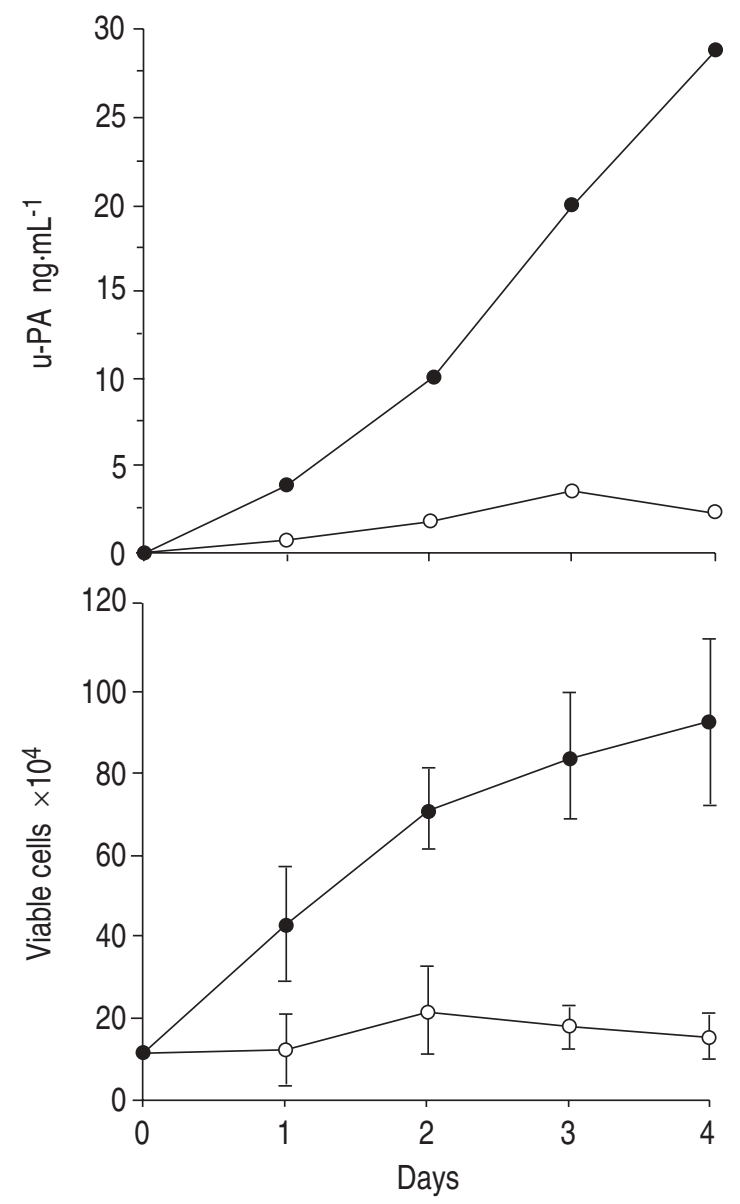

Fig. 4. - Production of urokinase-type plasminogen activator (u-PA) by TKB-30 cells, a cancer cell line derived from carcinomatous pleural fluid. TKB-30 cells $\left(10 \times 10^{4}\right)$ were plated into $9 \mathrm{~cm}^{2}$ tissue culture dishes. After preincubation for 2 days, the culture medium was changed and cultured with 5\% FBS (- - ) or $0 \%$ FBS (-Ofor 4 days. The cell numbers were determined by haemocytometer counts in triplicate. FBS: foetal bovine serum.

with tuberculous pleuritis, and one of two patients with parapneumonic pleuritis, a low level of u-PA was found (0.5 and $0.6 \mathrm{ng} \cdot \mathrm{mL}^{-1}$, respectively). u-PA was detected in pleural fluids in all of these 12 patients $(4.2 \pm 2.8$ $\left.\mathrm{ng} \cdot \mathrm{mL}^{-1}\right)$.

When the same study was performed using TKB-30 cells, u-PA levels in the culture supernatants increased in association with the number of viable cancer cells (fig. 4).

The immunocytochemical study showed the localization of u-PA in viable cells isolated from pleural fluid. Strong cytoplasmic staining of u-PA was demonstrated in cancer cells of all six patients. Mesothelial cells from all four patients with tuberculous pleuritis showed varied cytoplasmic staining, whilst there was no staining in lymphocytes and neutrophils.

\section{Discussion}

The fibrinolytic system in pleural fluids was first studied by Agrenius et al. [20], who showed that PAI-1 plays an important role in the regulation of fibrinolysis. We have previously studied the levels of tissue-type plasminogen activator (t-PA) and PAI-1 in pleural fluids, and demonstrated that not only in malignant but also in inflamed exudates those levels were higher than those in transudates due to CHF [9]. IDELL et al. [10] reported that u-PA levels were increased in all pleural exudates as compared to transudates, whereas t-PA levels were increased only in carcinomatous pleural fluid. There is one report in the literature of increased fibrinolytic activity in the pleural transudates of a patient with CHF, partly due to urokinase [21]. Recently, PhiliP-Joet et al. [11] reported that both u-PA and t-PA levels were increased in malignant effusions, particularly in those due to lymphoma; their study included various types of neoplastic diseases. Since the involvement of u-PA in carcinomatous and inflamed pleuritis has not yët been fully elucidated, we undertook the present study, in which we investigated pleural fluids in pulmonary adenocarcinoma, the leading cause of malignant pleural effusion [22, 23], and in tuberculosis as well as parapneumonic pleuritis.

Firstly, we found that the levels of u-PA in carcinomatous pleuritis were significantly higher than those in transudates due to CHF; however, u-PA levels were not statistically different between patients with cancer and tuberculosis, or between patients with cancer and pneumonia. Therefore, we consider that u-PA is not a useful clinical parameter in distinguishing carcinomatous pleuritis from benign pleuritis. In Western blot analysis, the observed MW was $55 \mathrm{kDa}$ both in malignant and inflamed pleural fluids. Weak and broad bands ranging $80-90 \mathrm{kDa}$ were also noted, which were considered to be intact complexes of u-PA and PA-inhibitors [21].

Secondly, there was a significant difference between u-PA levels in pleural fluids in the nonresponders to chemical pleurodesis and those in the responders. In other words, the results suggest that elevated u-PA levels in carcinomatous pleuritis would provide clinical information about the outcome of chemical pleurodesis. The complete response rate $(48 \%)$ in this study using OK-432 as sclerosing agent, was disappointing as compared to the results with other agents commonly used in the United States or Europe, such as tetracycline, talc or bleomycin. Since the levels of u-PA were only examined in carcinomatous pleuritis due to pulmonary adenocarcinoma, our conclusions might not be applied to other types of lung cancer or to pleural metastasis of 
nonpulmonary tumours. Further prospective studies will be needed to confirm the results of this study.

Recently, there have been other reports concerning the relationship between the fibrinolytic system and chemical pleurodesis or pleural symphysis [10, 20]. RODRIGUEZ-PANADERO et al. [24] demonstrated that increased pleural fibrinolytic activity, as expressed by D-dimer levels, is associated with failure of pleurodesis, despite significant inhibitory activity of PAI [24]. They suggested that there is a strong fibrinolytic action from cancer cells in the pleural space, leading to an imbalance between PA and PAI that results in increased fibrinolytic activity [24]. On the other hand, STRANGE et al. [21] tested early intrapleural instillation of u-PA or heparin to interrupt formation of pleural adhesion induced by tetracycline in rabbits. Intrapleural instillation of u-PA or heparin were equally effective in decreasing intrapleural adhesion in tetracycline-induced pleural injury. Their results indicated that early fibrinolytic intervention can attenuate subsequent pleural symphysis. Taking these results together with our own, we agree with the hypothesis that an increased endopleural fibrinolysis due to the u-PA and PAI system would lead to failure of pleurodesis, and intervention in the fibrinolytic system would change the results of pleural symphysis [21].

Finally, we demonstrated that u-PA is present in the culture supernatants of viable pleural cells containing cancer cells or mesothelial cells. Immunocytochemical study also showed cytoplasmic staining of u-PA in these cells. The human pulmonary adenocarcinomatous cell line, TKB-30 cell, derived from carcinomatous pleural fluid released u-PA in a dose-dependent manner, and immunostaining of the cell line also showed u-PA in the cytoplasm. Furthermore, the synthesis of u-PA from human cancer cells has been confirmed by the presence of messenger ribonucleic acid (m-RNA) [25]. Therefore, part of u-PA in pleural fluids might be derived from cancer cells and mesothelial cells in the pleural space. However, we cannot exclude the possibility that the cells may have taken up u-PA from the pleural fluid and stored it in their cytoplasm, since the results from this study are not definite proof of production of u-PA by these cells.

There was a discrepancy between in vivo and in vitro levels of u-PA. Although u-PA was demonstrated in all pleural effusions, it was not always present in the culture supernatants of pleural cells. u-PA was not detected in the culture supernatants from 1 of the 6 patients with carcinomatous pleuritis and from 3 of the 4 patients with tuberculous pleuritis. However, the immunostaining showed u-PA in the cytoplasm of cancer cells and mesothelial cells in these patients, which might reflect differences in the release of u-PA from these cells.

The sources of u-PA in pleural spaces are not known, but it may be derived either from pleural cells and/or the circulation. The interaction of cells through cytokines and growth factors [26] may be involved in the local production and exudation of u-PA. Since the environment in the present culture system was totally different from that in in vivo pleural spaces, it would be difficult to compare in vivo and in vitro u-PA levels. Further studies will be required to determine the mechanisms for the in vivo and in vitro production of u-PA.
In conclusion, our study suggests that local release of urokinase-type plasminogen activator by viable cells including cancer cells and mesothelial cells may affect urokinase-type plasminogen activator levels in pleural effusions.

Acknowledgements: The authors wish to thank T. Kamimuro, T. Iijima, M. Noro, Y. Nakamura, and H. Horiguchi for their help in preparing this manuscript.

\section{References}

1. Cajot JF, Kruithof EKO, Schleuning WD, Sordat B, Bachmann F. Plasminogen activators, plasminogen activator inhibitors and procoagulant analyzed in twenty human tumor cell lines. Int J Cancer 1986; 38: 719-727.

2. Hart DA, Rehemtulla A. Plasminogen activators and their inhibitors: regulators of extracellular proteolysis and cell function. Comp Biochem Physiol (B) 1988; 90: 691-708.

3. Sappino AP, Busso N, Belin D, Vassalli JD. Increase of urokinase-type plasminogen activator gene expression in human lung and breast carcinomas. Cancer Res 1987; 47: 4043-4046.

4. Suzumiya J, Hasui Y, Kohga S, Sumiyoshi A, Hashida S, Ishikawa E. Comparative study of plasminogen activator antigens in colonic carcinomas and adenomas. Int J Cancer 1988; 42: 627-632.

5. de Bruin PAF, Griffioen G, Verspaget HW, et al. Plasminogen activator profiles in neoplastic tissues of the human colon. Cancer Res 1988; 48: 4520-4524.

6. Hasui Y, Marutsuka K, Suzumiya J, Kitada S, Osada Y, Sumiyoshi A. The content of urokinase-type plasminogen activator antigen as a prognostic factor in urinary bladder cancer. Int J Cancer 1992; 50: 871-873.

7. Duffy MJ, Reilly D, O'Sullivan C, O'Higgins N, Fennelly JJ, Andreasen P. Urokinase-plasminogen activator, a new and independent prognostic marker in breast cancer. Cancer Res 1990; 50: 6827-6829.

8. Markus G, Takita H, Camiolo SM, Corasanti JG, Evers JL, Hobika GH. Content and characterization of plasminogen activators in human lung tumors and normal lung tissue. Cancer Res 1980; 40: 841-848.

9. Satoh H, Kamma H, Ogata T, Hasegawa S. Local production of plasminogen activator inhibitor-1 in carcinomatous pleuritis. Acta Oncol 1994; 33: 710-711.

10. Idell S, Girard W, Koenig KB, McLarty J, Fair DS. Abnormalities of pathways of fibrin turnover in the human pleural space. Am Rev Respir Dis 1991; 144: 187194.

11. Philip-Joët F, Alessi MC, Philip-Joët C, et al. Fibrinolytic and inflammatory processes in pleural effusions. Eur Respir J 1995; 8: 1352-1356.

12. Luh KT, Yang PC, Kuo SH, Chang DB, Yu CJ, Lee LN. Comparison of OK-432 and mitomycin C pleurodesis for malignant pleural effusion caused by lung cancer. Cancer 1992; 69: 674-679.

13. Paladine W, Cunningham TJ, Sponzo R, Donavan M, Olson K, Horton J. Intracavitary bleomycin in the management of malignant effusions. Cancer 1976; 38: 1903-1908.

14. Broaddus VC, Hébert CA, Vitangcol RV, Hoeffel JM, Bernstein MS, Boylan AM. Interleukin-8 is a major neutrophil chemotactic factor in pleural liquid of patients with empyema. Am Rev Respir Dis 1992; 146: 825830.

15. Light RW, MacGregor MI, Luchsinger PC, Ball WC. 
Pleural effusions: the diagnostic separation of transudates and exudates. Ann Intern Med 1972; 77: 507-513.

16. Satoh H, Ishikawa H, Funayama Y, Yazawa T, Ogata T, Hasegawa S. Combination cytotoxic effects of 5-fluorouracil and carboplatin against human lung cancer cell lines. Cancer Res Therapy Control 1995; 4: 199-202.

17. Hollas W, Blasi F, Boyd D. Role of the urokinase receptor in facilitating extracellular matrix invasion by cultured colon cancer. Cancer Res 1991; 51: 3690-3695.

18. Wu R, Martin WR, Robinson CB, et al. Expression of mucin synthesis and secretion in human tracheobronchial epithelial cells grown in culture. Am J Respir Cell Mol Biol 1990; 3: 467-478.

19. Swets JA. Measuring the accuracy of diagnostic systems. Science 1988; 240: 1285-1293.

20. Agrenius V, Chmielewska J, Widström O, Blombäck M. Pleural fibrinolytic activity is decreased in inflammation as demonstrated in quinacrine pleurodesis treatment of malignant pleural effusion. Am Rev Respir Dis 1989; 140: 1381-1385.
21. Strange C, Baumann MH, Sahn SA, Idell S. Effects of intrapleural heparin or urokinase on the extent of tetracycline-induced pleural disease. Am J Respir Crit Care Med 1995; 151: 508-515.

22. Light RW. Pleural diseases. 2nd Edn. Philadelphia, Lea \& Febiger, 1990; pp. 97-115.

23. Vladutiu AO. Pleural effusion. Mount Kisco, NY, Futura, 1986; pp. 175-205.

24. Rodriguez-Panadero F, Segado A, Juan JM, Ayerbe R, Garcia IT, Castillo J. Failure of talc pleurodesis is associated with increased pleural fibrinolysis. Am J Respir Crit Care Med 1995; 151: 785-790.

25. Stoppelli MP, Verde P, Grimaldi G, Locatelli EK, Blasi F. Increase in urokinase plasminogen activator mRNA synthesis in human carcinoma cells is a primary effect of the potent tumor promoter, phorbol myristate acetate. J Cell Biol 1986; 102: 1235-1241.

26. Laiho M, Keski-Oja J. Growth factors in the regulation of pericellular proteolysis: a review. Cancer Res 1989; 49: 2533-2553. 